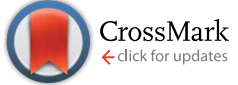

Cite this: RSC Adv., 2016, 6, 786

\title{
Photophysical and charge transport properties of pyrazolines $\dagger$
}

\begin{abstract}
Joseph Ajantha, ${ }^{\text {ab }}$ Elumalai Varathan, ${ }^{\text {abc }}$ Vishal Bharti, ${ }^{\text {bcd }}$
Venkatesan Subramanian, ${ }^{* a b c}$ Shanmugam Easwaramoorthi ${ }^{* a b c}$ and Suresh Chand ${ }^{\text {bcd }}$

Pyrazoline, an intense green emitting molecule both in solution and solid state, with extended $\pi$-conjugation has been synthesized via simple two-step reactions in high yields. Having the electron rich pyrazoline moiety with good redox behavior, pyrazolines can be potential candidates for charge transport material in organic electronic devices. UV-Visible absorption spectra of pyrazolines exhibit peaks below $400 \mathrm{~nm}$, which is a desired feature for charge transport materials because it avoids interference with donor absorption that falls in the visible to NIR region. Electrochemical and theoretical studies show that the HOMO energy level lies at around -4.8 to $5.2 \mathrm{eV}$ depending on the substituents, which is in fact compatible with the PEDOT:PSS/P3HT and work function of the ITO electrode. The experimental hole transport value, measured using the hole only device and space charge limited current (SCLC) method, was found to be in the range of $10^{-5}$ to $10^{-6} \mathrm{~cm}^{2} \mathrm{~V}^{-1} \mathrm{~s}^{-1}$, depending on the substituents. The maximum hole mobility calculated by theoretical methods for the pyrazolines is $0.75 \mathrm{~cm}^{2} \mathrm{~V}^{-1} \mathrm{~s}^{-1}$.
\end{abstract}

Received 22nd September 2015 Accepted 3rd December 2015

DOI: 10.1039/c5ra19520a

www.rsc.org/advances the overall efficiency of the devices for many reasons such as smoothening of the electrode surface, protection of the active layer from the electrode, and blocking of excitons. ${ }^{6}$ Significant progress has been made by several research groups in developing the charge carriers with high carrier mobility, stability, and durability. The most efficient and commonly used polymer based hole transport material is poly(3,4ethylenedioxythiophene):poly(styrenesulfonate) (PEDOT:PSS) due to its smooth anode surface, reduced current leakage, and higher device stability. However, hygroscopicity, ${ }^{7}$ unstable morphology, ${ }^{8}$ electrical inhomogeneity, ${ }^{9}$ intrinsic acidity, weak electron blocking, ${ }^{10}$ and low LUMO level ${ }^{11}$ of PEDOT:PSS restrict its application as an ideal hole transport material. Several attempts have been made to find alternative hole transport materials to PEDOT:PSS, which include metal oxides such as molybdenum oxide $\left(\mathrm{MoO}_{3}\right),{ }^{12}$ nickel oxide $\left(\mathrm{NiO}_{x}\right),{ }^{13}$ and vanadium oxide $\left(\mathrm{V}_{2} \mathrm{O}_{5}\right){ }^{14}$ The metal oxides have the capability to align with a wide range of energy levels, enabling them to form low-resistance ohmic contacts with the organic materials, high transparency, desirable band structure and excellent stability in ambient conditions, which can extend the lifetime of organic electronics. ${ }^{\mathbf{1 5}}$ However, harsh experimental conditions, such as high-temperature annealing ${ }^{\mathbf{1 6}}$ and vacuum deposition processes, required for metal oxides make them incompatible with the solution processes, and thus limit their practical applications. It is therefore desirable to develop suitable alternatives having better air- and thermal-stability, which are compatible with the solution-processable fabrication of solar cells. In this regard, a variety of small molecules have been 
developed as charge carriers, such as triarylamine derivatives, ${ }^{17,18}$ spirothioxanthene, ${ }^{19}$ phenothiazine ${ }^{20}$ and spiro-OMeTAD. ${ }^{21-23}$ Among them, triphenylamine (TPA) derivatives have been widely used as HTMs because of their efficient hole mobilities, high electron donating properties and excellent stability. ${ }^{\mathbf{2 4 , 2 5}}$ The charge carrier mobility of spiro-OMeTAD was found to be in the range of $10^{-5} \mathrm{~cm}^{2} \mathrm{~V}^{-1} \mathrm{~s}^{-1}$ to $10^{-3} \mathrm{~cm}^{2} \mathrm{~V}^{-1} \mathrm{~s}^{-1} \cdot{ }^{26,27}$ However, one of the suggested limitations of spiro-OMeTAD is low hole mobility, which causes excessive interfacial recombination losses. ${ }^{28,29}$ Nonetheless, spiro-OMeTAD continues to be the best performing candidate for HTM, but its higher cost associated with difficulties in its synthesis slow down the growth and advancement of high efficiency solar cells (Chart 1).

In this report, we have studied the photophysical and hole transport properties of a new class of compounds based on the pyrazoline skeleton. We have synthesized four pyrazolines with methoxy and allyloxy substituents at different positions. Pyrazolines, well-known brightening agents, ${ }^{27}$ are widely used in biological systems, synthetic fibers, fluorescent probes, chemosensors, hole transport materials, ${ }^{30,31}$ electrophotography, and electroluminescence, ${ }^{32,33}$ owing to their strong fluorescence and blue emitting properties. Pyrazoline derivatives are synthetically accessible, thermally and environmentally stable and absorb at considerably shorter wavelengths. The pyrazoline derivatives with high glass transition temperatures $\left(T_{\mathrm{g}}\right)$ have been known as excellent hole transport materials in organic electroluminescent devices. ${ }^{34,35}$ Higher hole mobilities in pyrazoline doped polymers have also been reported. ${ }^{36}$ Polymerbased hole transport materials have advantages like chemical and thermal stability, but these molecules have disadvantages of poor solubility and lower power conversion efficiency. Different electron donating groups have been selected to unravel the hole transport properties in organic solar cells. Their unique properties, such as rich electron density, ease of modulation of redox behavior, excellent spectral properties along with the judicious choice of substituents, have been the criteria for efficient hole transporting materials. In particular, their influences on their electronic energy levels and ionization potentials have been investigated to develop better holetransport materials. Both experimental and theoretical

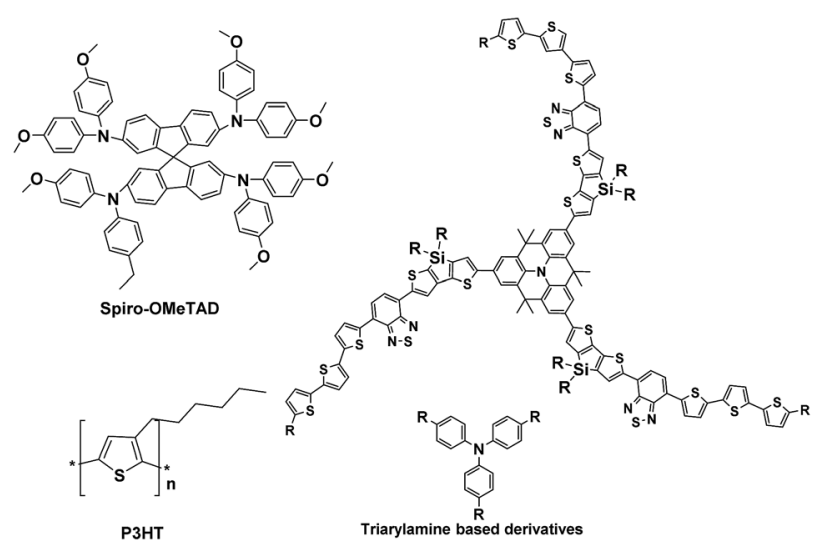

Chart 1 Molecular structures of different HTMs.

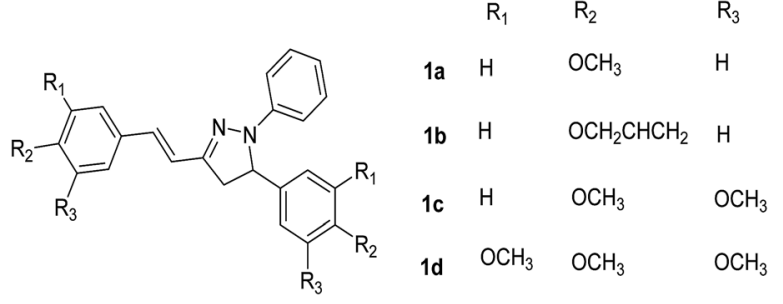

Chart 2 Synthesized molecules.

approaches have been employed to characterize the synthesized compounds and to understand the structure-property relationships (Chart 2).

\section{Results and discussion}

Synthesis of the pyrazolines was accomplished by a simple, efficient, two-step process outlined in Scheme 1. The intermediate compound 1,5-diphenylpenta-1,4-dien-3-one derivatives (B) and pyrazolines were synthesized according to a reported procedure. ${ }^{37,38}$ Briefly, Claisen-Schmidt condensation of 1 mole of acetone with 2 moles of substituted aromatic aldehyde (C) in $30 \mathrm{~mL}$ of ethanol affords the corresponding 1,4-dien-3-one, derivative 'B', in excellent yields (90-95\%). Further treatment of ' $\mathrm{B}$ ' with excess phenyl hydrazine in acetic acid produces pyrazoline (A) as a yellow solid in $80-85 \%$ yield, and the crude product was purified by column chromatography over silica gel using hexane and ethylacetate $(90: 10, \mathrm{v} / \mathrm{v})$ as eluent.

The IR spectra of dibenzylideneacetones exhibit characteristic absorption bands corresponding to $\alpha, \beta$-unsaturated ketones $\left(1650-1680 \mathrm{~cm}^{-1}\right)$ and trans $\mathrm{C}=\mathrm{C}\left(970-990 \mathrm{~cm}^{-1}\right)$. Pyrazolines show characteristic absorption bands in FTIR spectra at $1590-1600 \mathrm{~cm}^{-1}$ and $1310-1330 \mathrm{~cm}^{-1}$, due to $\mathrm{C}=\mathrm{N}$ and $\mathrm{C}-\mathrm{N}$ moieties, respectively. The compounds were also characterized using ${ }^{1} \mathrm{H}$ and ${ }^{13} \mathrm{C}$ NMR spectra (ESI $\dagger$ ).

The thermal stabilities of the pyrazolines 1a-1d were determined by DSC and TGA measurements (Fig. 1) and the data are given in Table 1. The glass transition temperatures of all the compounds were found to be in the range from $\sim 78$ to $95{ }^{\circ} \mathrm{C}$, with the exception of 1a. A second heating scan was performed to detect the decomposition temperature $\left(T_{\mathrm{d}}\right)$ by TGA. Decomposition temperatures of pyrazolines measured by TGA were found to be above $290{ }^{\circ} \mathrm{C}$, which would enable these materials to be processed at elevated temperatures during device fabrication. An endothermic peak observed at $88{ }^{\circ} \mathrm{C}$ for $\mathbf{1 b}$ in DSC has been ascribed to the melting point of the system, and the

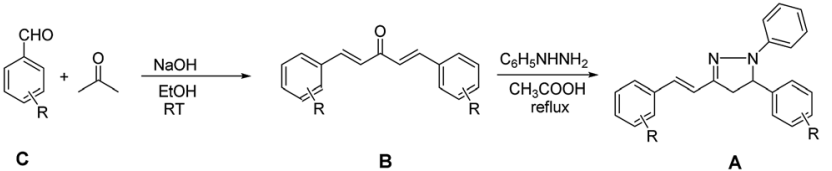

Scheme 1 Synthesis of 1,5-diphenyl-3-styryl-4,5-dihydro-1H-pyrazole derivatives. 

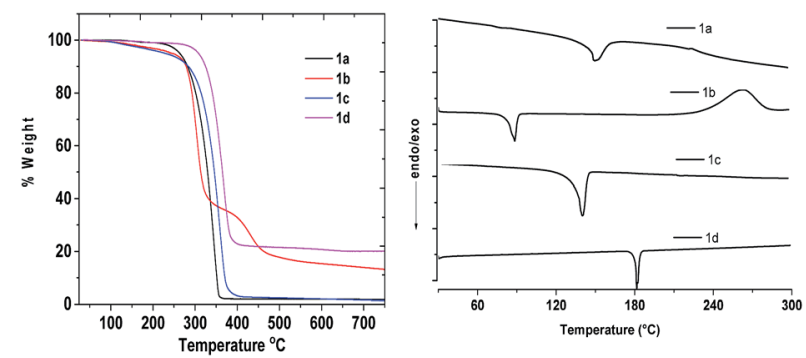

Fig. 1 TGA and DSC thermogram of pyrazolines $1 \mathrm{a}-1 \mathrm{~d}$ at scan rate of $10{ }^{\circ} \mathrm{C} \min ^{-1}$ in $\mathrm{N}_{2}$ atmosphere.

broad exothermic peak at $263{ }^{\circ} \mathrm{C}$ indicates the thermal polymerization of the allyloxy group.

Systematic UV-Visible and fluorescence spectral studies were carried out to understand the electronic properties of pyrazolines. The UV-Visible absorption spectra of 1a-1d in acetonitrile, as shown in Fig. 2, along with the results summarized in Table 2 indicate that there are no significant changes in the absorption spectra, except the molar extinction coefficient for the different substituents. The lowest energy peak observed at $381 \mathrm{~nm}$ has been assigned to the transition from singlet ground $\left(S_{0}\right)$ to the first singlet excited state $\left(S_{1}\right)$ and the band at $275 \mathrm{~nm}$ is ascribed to $S_{0} \rightarrow S_{2}$ transition.

The absorption maxima of 1a-1d were found to be redshifted when compared to the structurally similar chromophores based on pyrazolinopiperidines, wherein the five membered pyrazoline ring is fused with the piperidine moiety. ${ }^{38}$ This difference can be attributed to the enhanced planarity of the pyrazolines studied here compared to the reported compound, which eventually increases the $\pi$-conjugation throughout the molecule and reduces the energy gap between the ground and first excited singlet state. Nevertheless, the absorption onset for the derivatives lies below $400 \mathrm{~nm}$; thus, it is not expected to interfere with the absorption of the donor materials of organic solar cells, which generally appears in the visible-NIR region. Further, 1a-1d exhibit intense yellowish green fluorescence with a maximum at $475 \pm 5 \mathrm{~nm}$ in both solution and solid state.

Interestingly, 1a-1d have negligible overlap in absorption and fluorescence spectra, as can be seen from Fig. 2, with large Stokes shift values over $5000 \mathrm{~cm}^{-1}$.

Non-overlapping absorption and emission spectra are highly desirable for molecules to be used as fluorescent probes in microscopic applications. The fluorescence quantum yield was

Table 1 Thermal characteristics of compounds $1 \mathrm{a}-1 \mathrm{~d}$

\begin{tabular}{llcl}
\hline Compound & $T_{\mathrm{g}}{ }^{a}\left({ }^{\circ} \mathrm{C}\right)$ & $T_{\mathrm{m}}{ }^{a}\left({ }^{\circ} \mathrm{C}\right)$ & $T_{\mathrm{ID}}\left({ }^{\circ} \mathrm{C}\right)$ \\
\hline 1a & 79 & 151 & 267 \\
1b & NA & 88 & 271 \\
1c & 95 & 142 & 286 \\
1d & 80 & 183 & 309
\end{tabular}

${ }^{a}$ Determined by DSC, scan rate $10{ }^{\circ} \mathrm{C} \mathrm{min}^{-1}, \mathrm{~N}_{2}$ atmosphere. $T_{\mathrm{m}}$, temperature at melting; $T_{\mathrm{g}}$, glass-transition temperature; and $T_{\mathrm{ID}}$, thermal decomposition onset. determined to be $0.19 \pm 0.2$ with respect to quinine sulphate (0.05 $\mathrm{M} \mathrm{H}_{2} \mathrm{SO}_{4}$ ) in water. ${ }^{39}$ The fluorescence lifetimes were measured by exciting the sample at $375 \mathrm{~nm}$ with $100 \mathrm{ps}$ pulsed light, and the decay profiles monitored at respective maximum emission wavelengths are given in Fig. S2. $\dagger$ The decay profiles were fitted satisfactorily with single exponential function $\left(\psi^{2}=\right.$ 1 to 1.2 ) and fluorescence lifetimes of $2.95,3.65,2.84,2.83 \mathrm{~ns}$ were obtained for $\mathbf{1 a}, \mathbf{1 b}, \mathbf{1} \mathbf{c}$, and $\mathbf{1 d}$, respectively. The radiative and non-radiative rate constants calculated from fluorescence quantum yields and lifetimes were found to be insensitive to the nature of the substituents (Table 2).

The possibility of the intramolecular charge transfer interactions of these compounds was studied by measuring the steady state fluorescence spectra in solvents of different polarities. While the absorption spectra of pyrazolines 1a-1d were found to be insensitive, the fluorescence spectra show solvent polarity induced, red-shifted emission spectra characteristic of intramolecular charge transfer interactions (ESI, Fig. S1 \& Table $\mathrm{S} 1 \dagger)$. In this case, the pyrazoline and styrene moieties are expected to act as electron donor and acceptor components, respectively. This is also supported by the molecular orbital pictures of highest occupied (HOMO) and lowest unoccupied (LUMO) molecular orbitals, wherein electron density redistribution occurs during the HOMO $\rightarrow$ LUMO transition (vide infra). The data summarized in Table $\mathrm{S} 1 \dagger$ indicate that the number of methyl groups does not have any significant effect on the intramolecular charge transfer interactions.

The density functional theory (DFT) based calculations were carried out to obtain insight into the structure property relationship of these pyrazoline materials. The calculated frontier molecular orbital (FMO) distributions of molecules are shown in Fig. 3.

From Fig. 3, it can be observed that both HOMO and LUMO are localized on the whole molecules. However, close analysis of these orbitals reveals that HOMO is predominantly localized on the pyrazoline moiety and LUMO is localized on the styrene unit. As a result, there is a possibility for the intramolecular charge transfer transition between the pyrazoline to styrene unit, which can also be understood from solvent polarity dependent fluorescence studies.

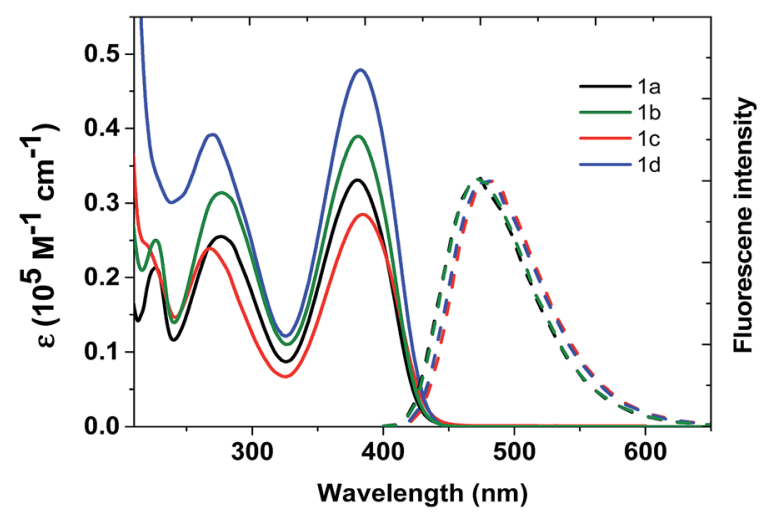

Fig. 2 UV-Visible absorption and fluorescence emission of pyrazoline derivatives $1 \mathrm{a}-1 \mathrm{~d}$ in acetonitrile solvent. 
Table 2 Photophysical properties of pyrazoline derivatives in acetonitrile solvent

\begin{tabular}{|c|c|c|c|c|c|c|c|}
\hline Cmpd & $\begin{array}{l}\lambda_{\mathrm{abs}} \mathrm{nm} \\
\left(\varepsilon 10^{4} \mathrm{M}^{-1} \mathrm{~cm}^{-1}\right)\end{array}$ & $\lambda_{\mathrm{fl}} \mathrm{nm}$ & $\begin{array}{l}\text { Stokes shift } \\
\left(\mathrm{cm}^{-1}\right)\end{array}$ & $\begin{array}{l}\tau_{\mathrm{fl}} \\
(\mathrm{ns})\end{array}$ & $\Phi_{\mathrm{fl}}$ & $\begin{array}{l}K_{\mathrm{r}} \\
{\left[10^{8} \mathrm{~s}^{-1}\right]}\end{array}$ & $\begin{array}{l}K_{\mathrm{nr}} \\
{\left[10^{8} \mathrm{~s}^{-1}\right]}\end{array}$ \\
\hline $1 \mathbf{a}$ & 225 (2.14), 275 (2.13), 381 (3.30) & 472 & 5060 & 2.95 & 0.19 & 0.56 & 2.77 \\
\hline $\mathbf{1 b}$ & 227 (2.49), 285 (3.14), 381 (3.91) & 474 & 5150 & 3.65 & 0.18 & 0.49 & 2.24 \\
\hline 1c & $265(2.38), 385(2.86)$ & 480 & 5270 & 2.84 & 0.17 & 0.53 & 2.63 \\
\hline 1d & $304(3.90), 383(4.80)$ & 481 & 5320 & 2.83 & 0.19 & 0.61 & 2.62 \\
\hline
\end{tabular}

To understand the suitability of these molecules as charge carriers, electrochemical properties were studied using cyclic voltammetry and differential pulse voltammetry (DPV), using glassy carbon as the working electrode, platinum wire as the counter electrode and tetrabutylammonium hexafluorophosphate as the supporting electrolyte. The energy of the HOMO was calibrated using the half wave potential of the ferrocene/ferrocenium redox couple, which is $-4.5 \mathrm{eV}$ below vacuum..$^{40}$ The DPV of pyrazolines in homogeneous solution is given in Fig. 4 and the findings are summarized in Table 3. The first oxidation potentials of $\mathbf{1 a}, \mathbf{1 b}, \mathbf{1 c}$, and $\mathbf{1 d}$ in acetonitrile solution were measured to be $0.74,0.62,0.44$, and $0.67 \mathrm{~V}$, respectively, with reference to the $\mathrm{Fc} / \mathrm{Fc}^{+}$redox couple. The first oxidation peak might have originated from the loss of electrons from pyrazoline nitrogens. The HOMO values calculated from the electrochemical data based on the empirical formula HOMO $=-\left(E_{\text {ox. onset }}+4.5\right)(\mathrm{eV})$ corresponds to $-5.24,-4.88$, $-5.02,-5.07 \mathrm{eV}$ for $\mathbf{1 a}, \mathbf{1 b}, \mathbf{1 c}$, and $\mathbf{1 d}$, respectively.

These values are in accordance with the work function of the ITO electrode (4.5-4.7 eV), and are also comparable to the HOMO of the widely used hole transport material PEDOT:PSS (5.1-5.4 eV). ${ }^{41}$ Furthermore, the significantly higher HOMO energy levels of 1a-1d than the acceptor PCBM $(\mathrm{HOMO}=-6.10$

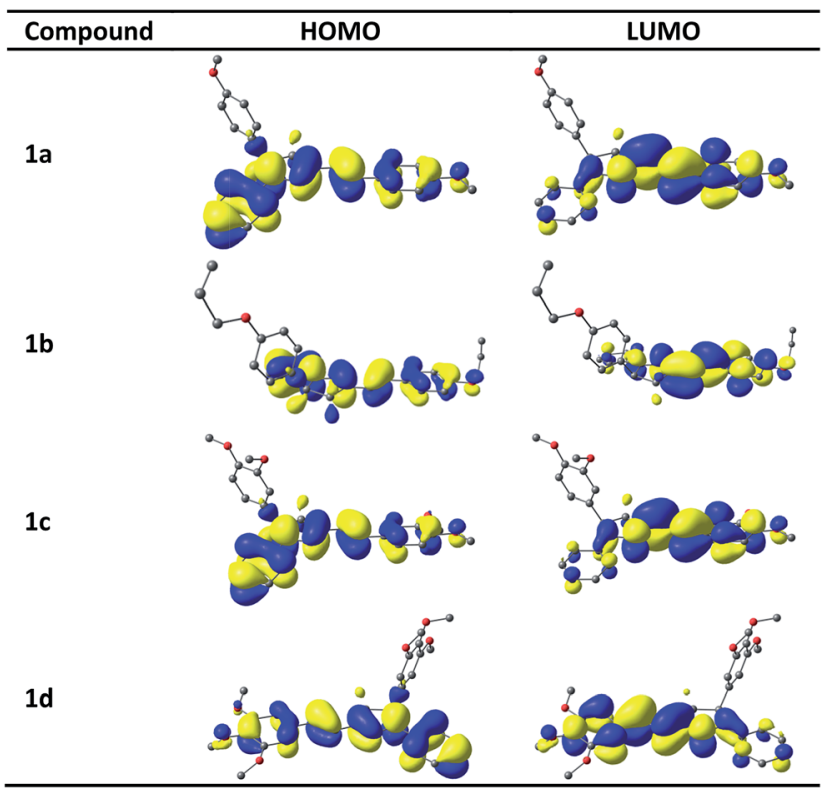

Fig. 3 Contour plots (isosurface value $=0.025 \mathrm{au}$ ) of the $\mathrm{HOMO}$ and LUMO levels of designed hole transport molecules at the B3LYP/631G* level. The hydrogen atoms are omitted here for clarity.
$\mathrm{eV} ; \mathrm{LUMO}=-3.70 \mathrm{eV})^{\mathbf{4 2}}$ are expected to facilitate the electron transfer process between the hole transport layer and acceptor layer. The electrochemical stability of the components was understood from the constant redox behavior upon repeated reduction-oxidation cycles. HOMO-LUMO band gaps for $\mathbf{1 a}, \mathbf{1 b}$, 1c, and 1d calculated from electrochemical methods were found to be $1.66,1.81,1.50$, and $2.79 \mathrm{eV}$, respectively, which are in close agreement with those obtained by the optical method. The energy level diagram of the components is shown in Fig. 5.

The charge-carrier (hole and electron) mobility is a key factor in deciding the efficiency of organic solar cells. It has been evident from the previous studies that the charge mobility of organic molecules can be described well by the incoherent hopping model, ${ }^{\mathbf{1 4 3}-45}$ where charge transport is viewed as a charge exchange reaction:

$$
\mathrm{M}^{\mathrm{n}}+\mathrm{M}^{\mathrm{i}} \rightarrow \mathrm{M}^{\mathrm{i}}+\mathrm{M}^{\mathrm{n}}
$$

where $\mathbf{M}^{\mathrm{n}}$ represents the neutral state of the system and $\mathbf{M}^{\mathrm{i}}$ represents the ionic state of the system. The hole/electron transfer rate can be expressed by the standard Marcus-Hush, expressed as eqn (2). ${ }^{46-48}$

$$
\begin{aligned}
K_{\text {hole/electron }}= & \left(\frac{4 \pi^{2}}{h}\right) \frac{1}{\sqrt{4 \pi k_{\mathrm{B}} T \lambda_{\text {hole/electron }}}} V^{2} \\
& \times \exp \left(-\frac{\lambda_{\text {hole/electron }}}{4 k_{\mathrm{B}} T}\right)
\end{aligned}
$$

where $T$ is the temperature, $\lambda$ is the reorganization energy, $V$ is the electronic coupling matrix element (transfer integral)

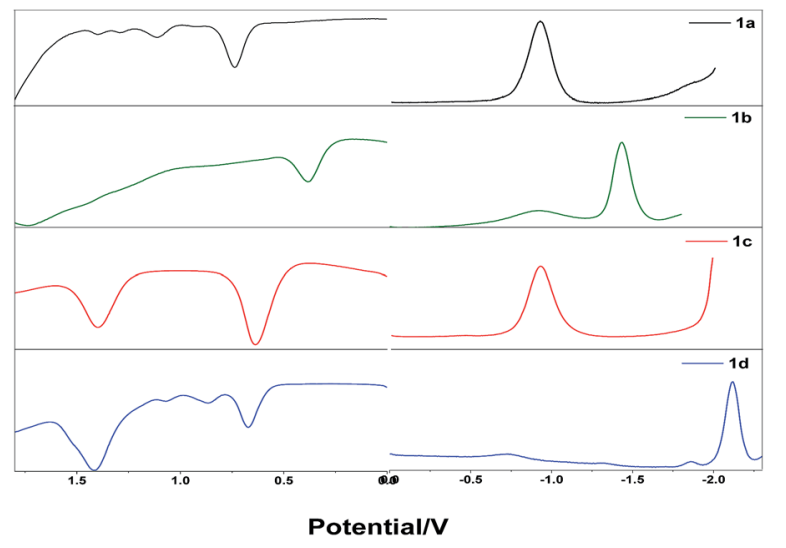

Fig. 4 Differential pulse voltammograms (dpv) of pyrazolines 1a-1d $\left(10^{-3} \mathrm{M}\right.$ solutions, scan rate of $100 \mathrm{mV} \mathrm{s}^{-1} \mathrm{vs}$. $\left.\mathrm{Ag} / \mathrm{Ag}^{+}\right)$in $0.1 \mathrm{M}$ solution of tetrabutylammonium hexafluorophosphate in acetonitrile. 
Table 3 Electrochemical, theoretical HOMO-LUMO and free energy changes for the electron transfer processes of pyrazolines

\begin{tabular}{|c|c|c|c|c|c|c|c|c|c|}
\hline Compd & $E_{\mathrm{Ox}}{ }^{a}(\mathrm{~V})$ & $E_{\text {red }}^{a}(\mathrm{~V})$ & $E_{\text {Номо }}^{b}(\mathrm{eV})$ & $E_{\mathrm{LUMO}}^{c}(\mathrm{eV})$ & $E_{\mathrm{g}}^{c}(\mathrm{eV})$ & $E_{\text {номо }}{ }^{d}(\mathrm{eV})$ & $E_{\text {LUMO }}^{d}(\mathrm{eV})$ & $E_{\mathrm{g}}{ }^{e}(\mathrm{eV})$ & $E_{\mathrm{g}}^{f}(\mathrm{eV})$ \\
\hline $1 \mathrm{a}$ & 0.74 & -0.92 & -5.24 & -3.58 & -1.6 & -4.59 & -1.38 & -3.21 & -2.75 \\
\hline $1 b$ & 0.38 & -1.43 & -4.88 & -3.07 & -1.8 & -4.57 & -1.37 & -3.20 & -2.74 \\
\hline $1 d$ & 0.67 & -2.12 & -5.07 & -2.28 & -2.7 & -5.47 & -2.23 & -3.24 & -2.77 \\
\hline
\end{tabular}

${ }^{a}$ The redox potential of compounds obtained from differential pulse voltammetry using glassy carbon as the working electrode with reference to the $\mathrm{Fc} / \mathrm{Fc}^{+}$couple. $0.1 \mathrm{M}$ tetrabutylmmonium hexaflurophosphate was used as a supporting electrolyte. ${ }^{b} E_{\mathrm{HOMO} / \mathrm{LUMO}}=\mathrm{HOMO}$ and LUMO energy levels calculated from the redox potentials. ${ }^{c} E_{\mathrm{g}}=$ electrochemical HOMO-LUMO energy gap. ${ }^{d}$ HOMO and LUMO energy calculated using Gaussian 09 programme at B3LYP/6-31G level. ${ }^{e}$ Computed HOMO-LUMO energy gap. ${ }^{f}$ Optical HOMO-LUMO energy gap (zero-zero transition energy estimated from the point of intersection of normalized absorption and emission spectra in acetonitrile).

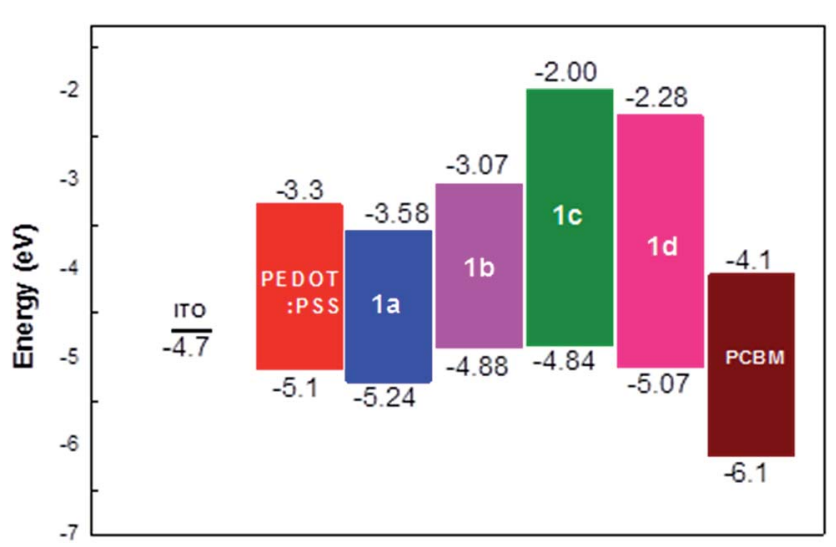

Fig. 5 Energy level diagram of the corresponding materials in $\mathrm{BHJ}$ OSCs.

between neighboring molecules in an organic single crystal, $h$ is the Planck constant and $k_{\mathrm{B}}$ is the Boltzmann constant. It is evident from eqn (2) that there are two key parameters that determine the charge transfer rate, $\lambda$ and $V$. Theoretical investigations on the charge transport properties of several organic materials imply that both $V$ and $\lambda$ are equally responsible for the charge transfer properties. Thus, these two parameters need to be properly tuned to obtain the desired properties. Molecules having maximum transfer integral with minimum $V_{\mathrm{ab}}$ are expected to show optimal transport properties. The total reorganization energy of the molecule is given by the sum of internal and external reorganization energies. The former term involves the contributions from intramolecular geometry vibrations and the latter term describes the change in electronic polarization of the surrounding medium. The external reorganization energy can be neglected because most of the organic materials have low polarity, and therefore the main contribution to the total reorganization energy would be from internal reorganization. In this study, the internal reorganization energy (for holes and electrons) is calculated by using eqn (3) and (4), and is schematically depicted in scheme 2 .

$$
\begin{aligned}
& \lambda_{+}=\lambda_{1}+\lambda_{2} \\
& \lambda_{-}=\lambda_{3}+\lambda_{4}
\end{aligned}
$$

$$
\begin{aligned}
\lambda_{1}= & E^{+}\left(\mathrm{M}_{0}\right)-E^{+}\left(\mathrm{M}^{+}\right) ; \lambda_{1}=E^{0}\left(\mathrm{M}^{+}\right)-E^{0}\left(\mathrm{M}_{0}\right) \lambda_{3}=E^{-}\left(\mathrm{M}_{0}\right) \\
& -E^{-}\left(\mathrm{M}^{+}\right) ; \lambda_{1}=E^{0}\left(\mathrm{M}^{+}\right)-E^{0}\left(\mathrm{M}_{0}\right)
\end{aligned}
$$

where $E^{0}\left(\mathrm{M}_{0}\right), E^{+}\left(\mathrm{M}^{+}\right)$, and $E^{-}\left(\mathbf{M}^{-}\right)$, respectively, denote the total energy of neutral, cationic, and anionic species at their optimized geometries. $E^{+}\left(\mathrm{M}_{0}\right)$ and $E^{0}\left(\mathrm{M}^{+}\right)$denote the total energy of the cationic and neutral species at their optimized geometry of $\mathrm{M}_{0}$ and $\mathrm{M}^{+}$, respectively. Similarly, $E^{-}\left(\mathrm{M}_{0}\right)$ and $E^{0}\left(\mathrm{M}^{-}\right)$represent the total energy of the anionic and neutral species at the optimized geometry of $\mathbf{M}_{0}$ and $\mathbf{M}^{-}$, respectively. The reorganization energies for electrons $\left(\lambda_{-}\right)$and holes $\left(\lambda_{+}\right)$of the molecules were computed at the B3LYP/6-31G* level using the Gaussian 09 program. ${ }^{49,50}$ It has been evident from the previous studies that the B3LYP functional with $6-31 \mathrm{G}^{*}$ basis set provides the most reliable results on the reorganization of organic molecules. ${ }^{25,48,51-53}$

The transfer integral $V_{\mathrm{ab}}$ represents the strength of electronic coupling between the two adjacent neighboring molecules a and b. $V_{\mathrm{ab}}$ can be calculated based on Koopmans' theorem ${ }^{54}$ by assuming that the interacting molecules are identical, symmetrically equivalent and also have the same site energies. This method has been most frequently used in the literature for the estimation of transfer integrals in organic semiconductors. ${ }^{1}$

$$
V_{\mathrm{ab}}=\frac{E_{\mathrm{H} / \mathrm{L}+1}-E_{\mathrm{H}-1 / \mathrm{L}}}{2}
$$

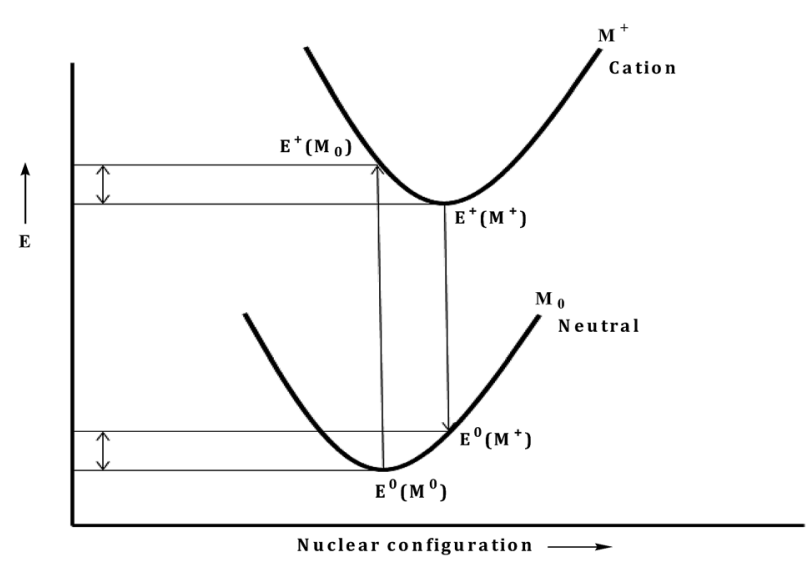

Scheme 2 Internal reorganization energy for holes $\left(\lambda_{h}\right)$ in arbitrary units. 
where $E_{\mathrm{H} / \mathrm{L}+1}$ and $\mathrm{E}_{\mathrm{H}-1 / \mathrm{L}}$ are the energies of HOMO/LUMO + 1 and HOMO - 1/LUMO, respectively, obtained from the closed shell configuration of the neutral states of two stacked pyrazoline molecules. Once the charge transfer rate is obtained by eqn (2), the hopping mobility can be estimated by the Einstein relation, expressed as eqn (6).

$$
\mu_{\text {hop }}=\frac{e D}{k_{\mathrm{B}} T}
$$

where $T$ is temperature, $k_{\mathrm{B}}$ is Boltzmann constant, and $D$ is the diffusion coefficient. The relation between $D$ and $k_{\mathrm{ct}}$ for a one dimensional system is given by $D=l^{2} k_{\mathrm{c}}$, where $l$ is the space distance between two interacting molecules.

Reorganization energy $(\lambda)$ is one of the important factors that govern the charge mobilities of the organic semiconductors. According to Marcus-Hush theory, lower $\lambda$ value is expected to yield higher charge mobility. Thus, understanding the geometric deformation becomes vital because it has significant influence on the reorganization energy of organic molecules. The calculated reorganization energies of pyrazoline molecules are listed in Table 4 . The electron reorganization energy $\left(\lambda_{-}\right)$is calculated to be $0.49,0.54,0.50$, and $0.54 \mathrm{eV}$ for 1a, 1b, 1c, and 1d, respectively. Similarly, the hole reorganization energy $\left(\lambda_{+}\right)$is found to be $0.32,0.33,0.35$, and $0.43 \mathrm{eV}$ for 1a, 1b, 1c, and 1d, respectively. For all the molecules studied here, the magnitude of the electron reorganization energy $\left(\lambda_{-}\right)$is found to be profoundly larger than its corresponding hole reorganization energy $\left(\lambda_{+}\right)$. This observation indicates that pyrazolines could be good hole transport materials rather than electron transport materials. We also examined the effect of substituents on $\lambda_{+}$values. It can be seen that 1a and $\mathbf{1 b}$ have comparatively lower hole reorganization energies than $\mathbf{1 c}$ and $\mathbf{1 d}$. The slightly higher reorganization energies for 1d than 1a are due to the slight deviation from planar geometry by the addition of more substituents on $R_{1}, R_{2}$ and $R_{3}$ positions.

The charge transfer integral $\left(V_{\mathrm{ab}}\right)$, a parameter that defines the electronic coupling between the two molecules, is influenced because of intermolecular stacking. Although the molecular stacking can generate a large number of conformations, having extended $\pi$-conjugation, the intermolecular stacking is expected to be dominantly influenced by the $\pi-\pi$ interactions.

Indeed, face-to-face $\pi$-stacking with a large orbital overlap facilitates the enhanced electronic coupling between the two adjacent molecules and consequently aids the inter-chain

Table 4 Calculated hole $\left(\lambda_{+}\right)$and electron $\left(\lambda_{-}\right)$reorganization energies of hole transporting materials at B3LYP/6-31G* level (energies in eV)

\begin{tabular}{|c|c|c|c|c|c|c|}
\hline \multirow[b]{2}{*}{ Compound } & \multicolumn{3}{|l|}{ Hole } & \multicolumn{3}{|c|}{ Electron } \\
\hline & $\lambda_{1}$ & $\lambda_{2}$ & $\lambda_{+}$ & $\lambda_{3}$ & $\lambda_{4}$ & $\lambda_{-}$ \\
\hline $1 \mathrm{a}$ & 0.16 & 0.15 & 0.32 & 0.25 & 0.24 & 0.49 \\
\hline $1 b$ & 0.17 & 0.16 & 0.33 & 0.25 & 0.28 & 0.54 \\
\hline $1 \mathrm{c}$ & 0.19 & 0.16 & 0.35 & 0.25 & 0.25 & 0.50 \\
\hline 1d & 0.23 & 0.20 & 0.43 & 0.26 & 0.28 & 0.54 \\
\hline
\end{tabular}

charge transport of an organic molecule. In the absence of any experimental results, two different methodologies have been used to compute the transfer integral $\left(V_{\mathrm{ab}}\right)$. In one method, the initial geometry of the two monomers is co-facially stacked at the distance of $\sim 3.5 \AA$, and then the structures are further optimized. The orbital energies required for charge transfer integral calculation are obtained from the optimized geometries. In the second case, the single point calculations of the two monomers are co-facially stacked at the distance of $\sim 3.5 \AA$. Electronic coupling values of all the dimers are calculated for the optimized structures of two adjacent dimers obtained at the M05-2X/6-31G* level of theory. Optimized structures of the dimers are shown in Fig. 6.

Charge transfer integrals $\left(V_{\mathrm{ab}}\right)$, charge transfer rates $(K)$, and hopping mobilities $(\mu)$ are calculated using eqn (2), (5), and (6), respectively, for all the dimers and results are given in Table 5 . The abovementioned calculations are performed at room temperature $(298 \mathrm{~K})$. As shown in Table 5 , both the charge transfer rate and the mobility have the same trend. Both are larger for holes compared to electrons, except for system 1c. Thus, these molecules might be good hole transport materials. The considerably larger $K$ and $\mu$ values for holes compared to electrons is due to small hole reorganization energies and larger electronic coupling. The calculated carrier mobility is quite consistent with the experimental values (vide infra). However, theoretical values provide an upper limit of the charge mobility values compared with experimentally reported one, although the trends remains the same (Table 6).

To understand the influence of charge carrier transport on photovoltaic performance, we used the space charge limited current (SCLC) method to measure the hole mobility in the blend. Fig. 7 shows the $J-V$ curves for hole only device configuration. The hole transport properties of pyrazolines $\mathbf{1 b}-\mathbf{1 d}$ were evaluated by measuring the charge carrier mobilities using hole only device configuration, viz., indium tin oxide (ITO)/ poly(3,4-ethylendioxythiophene)-poly(styrene sulfonate) (PEDOT:PSS)/hole transport layer (1b, 1c and 1d)/Au. PEDOT:PSS was spin-coated onto the cleaned ITO substrate and dried at $140{ }^{\circ} \mathrm{C}$ for $30 \mathrm{~min}$ in a vacuum.

The role of the PEDOT:PSS layer $(40 \mathrm{~nm})$ is to reduce the roughness of ITO as well as improve the work function to achieve better hole-only device properties. These active materials 1b, 1c and 1d were spin coated onto PEDOT:PSS from chloroform solution $\left(40 \mathrm{mg} \mathrm{mL}^{-1}\right)$ in a glove box. Finally, Au contacts (200 nm thick) were applied via thermal evaporation through a shadow mask in an $8 \times 10^{-6}$ Torr vacuum. The work functions of Au and ITO are close to the HOMO energy level of HTL materials, as well as far below the LUMO energy level. Therefore, the electron injection barrier is considerably high when compared to the hole injection barrier from both the electrodes. As a result, the transport is dominated by holes in the so-called hole only device. The $J-V$ characteristics of these samples were measured with a Keithley 2420 Source Meter unit interfaced with a PC at room temperature..$^{55-57}$

At low applied bias, the $J-V$ characteristics follow Ohm's law, [Fig. 7] as the injected holes density $p$ is negligible when 


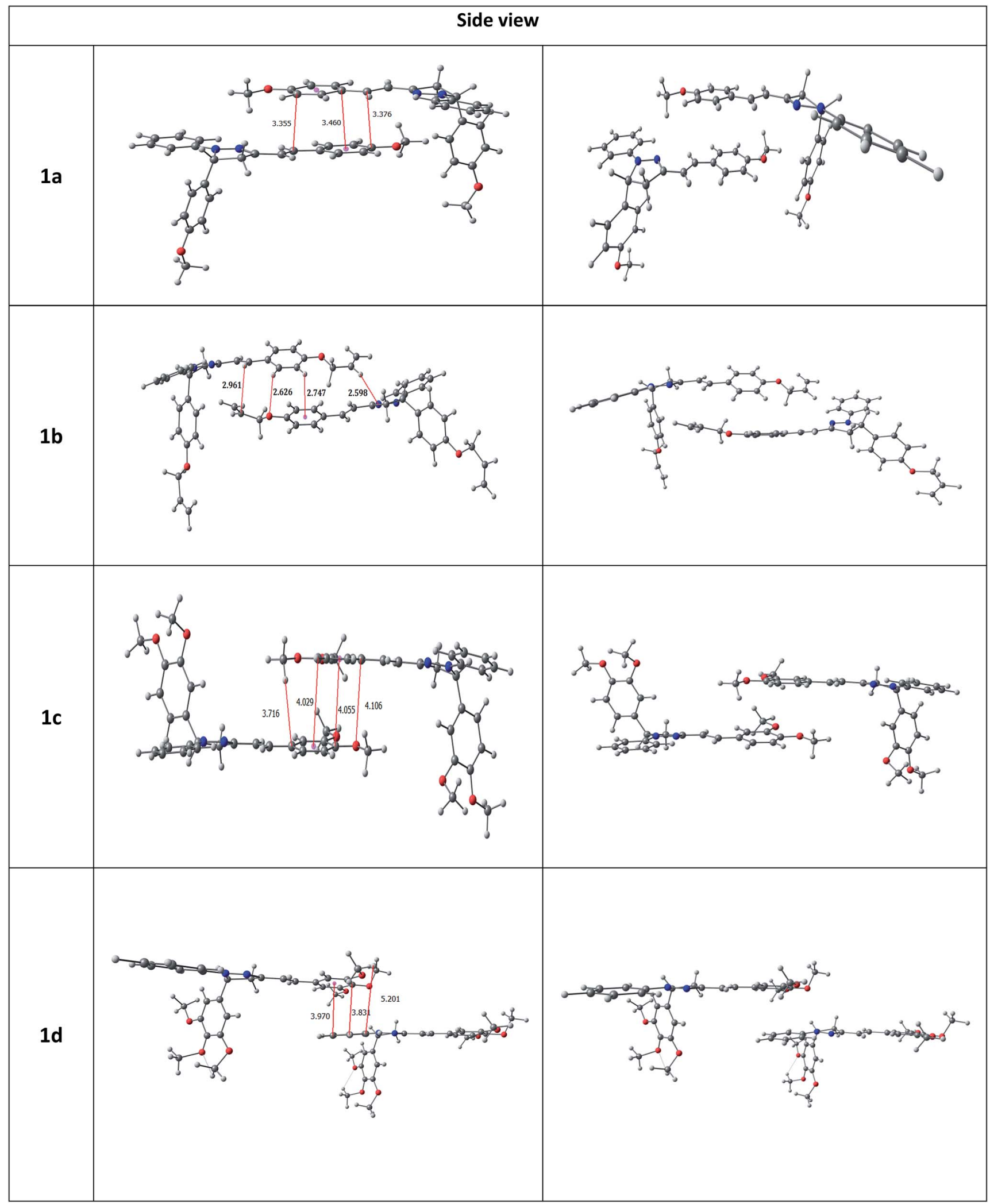

Fig. 6 Optimized geometry of dimers using M05-2X/6-31 method. 
Table 5 The charge transfer integrals $\left(V_{\mathrm{ab}}\right.$ in eV) and the average intermolecular distances (in $\AA$ ) for the M05-2X/6-31G* geometries optimized for the lowest energy dimer, reorganization energy $(\lambda)$, maximum transfer integral $(t)$, maximum rate of charge hopping $(K)$, and drift mobility $(\mu)$ for holes and electrons of hole transporting materials

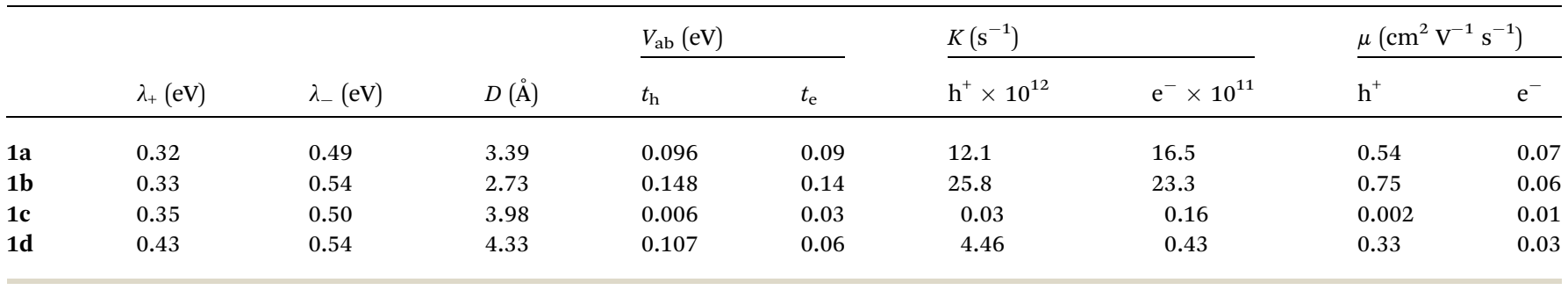

Table 6 Charge transport parameters in the samples generated by theoretical fitting of experimental curves

\begin{tabular}{lllll}
\hline Compd & $\mu\left(\mathrm{cm}^{2} \mathrm{~V}^{-1} \mathrm{~s}^{-1}\right)$ & $N_{v}\left(\mathrm{~cm}^{-3}\right)$ & $H_{\mathrm{b}}\left(\mathrm{cm}^{-3}\right)$ & $d(\mathrm{~nm})$ \\
\hline 1b & $1.5 \times 10^{-6}$ & - & - & 400 \\
1c & $3 \times 10^{-6}$ & $1 \times 10^{18}$ & $6 \times 10^{17}$ & 390 \\
1d & $4 \times 10^{-5}$ & $3 \times 10^{18}$ & $1.7 \times 10^{17}$ & 580
\end{tabular}

compared to the density of thermally generated holes inside the specimen. This is illustrated by the following equation:

$$
q p_{0} \mu \frac{V}{d}>\frac{9}{8} \varepsilon \mu \frac{V^{2}}{d^{3}}
$$

where $q$ is the electronic charge, $\mu$ is the carrier mobility, $d$ is the thickness of the film, and $\varepsilon$ is the permittivity of the material.

With the increase in applied voltage, the injected carrier density increases and a point is reached where it is equal to the thermally generated carrier density and thus the $J-V$ characteristics follow the space charge limited conduction (SCLC) mechanism. The onset voltage $\left(V_{\Omega}\right)$, which governs the transition from Ohm's law to SCLC is given as

$$
V_{\Omega}=\frac{8}{9} \frac{q p_{0} d^{2}}{\varepsilon}
$$

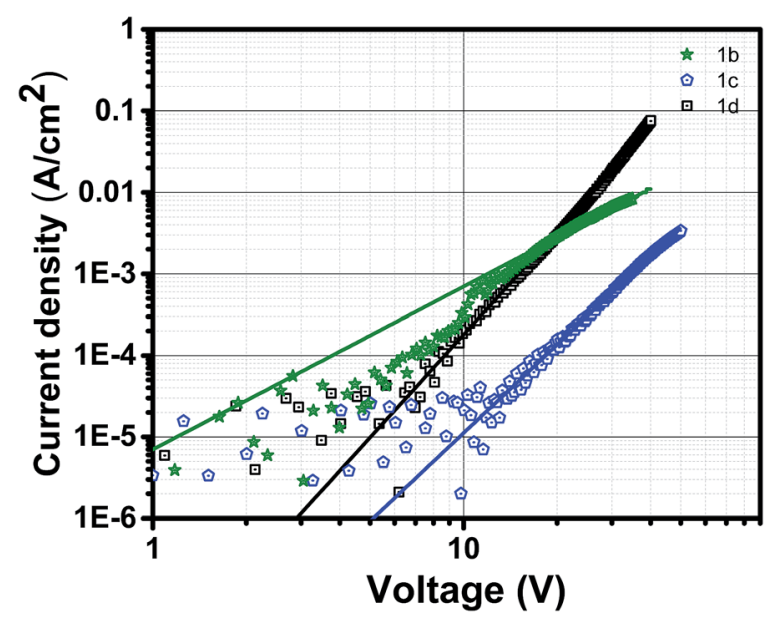

Fig. $7 \mathrm{~J}-V$ characteristics of devices, experimental (symbols) and theoretical fits (solid lines are obtained using eqn (3) and (4)). when the slope of the $J-V$ characteristics is $\sim 2$ and then the Mott-Gurney's equation is obeyed as follows:

$$
J=\frac{9}{8} \varepsilon \mu \frac{V^{2}}{d^{3}}
$$

The equation does not imply the absence of traps but reveals that up to a particular temperature, thermal energy is sufficient to fill all the traps.

When the slope of the characteristics is $>2$ and eqn (9) is not followed, it implies that now thermal energy is not sufficient to fill the traps. The $J-V$ characteristics follow the trap limited conduction with traps distributed exponentially in energy and space and is given as follows:

$$
J=q^{1-l} \mu N_{v}\left(\frac{2 l+1}{l+1}\right)^{l+1}\left(\frac{l}{l+1} \frac{\varepsilon \varepsilon_{0}}{H_{\mathrm{b}}}\right)^{l} \frac{V^{l+1}}{d^{2 l+1}}
$$

where $q$ is the elementary charge, $\mu$ is the charge carrier mobility, $N_{v}$ is the effective density of states, $d$ is the film thickness, $\varepsilon$ is the dielectric constant of the material, $\varepsilon_{0}$ is the permittivity of the free space, and $H_{\mathrm{b}}$ is the total trap density at the edge of the valence band.

The $J-V$ characteristics of three samples, viz., 1b, 1c, and 1d, are shown in Fig. 7. The experimental curve of $\mathbf{1 b}$ and $\mathbf{1 c}$ shows two regions of conduction that are ohmic conduction at a low voltage and trap limited conduction (non ohmic conduction) at a high voltage, and 1d shows trap-free SCLC conduction at the high voltage.

The theoretical curve generated using eqn (10) has been found to fit the experimental curve, as shown in Fig. 7 with charge transport parameters given as follows for all three samples. The hole mobility is measured to be $3 \times 10^{-6}, 4 \times$ $10^{-5}$, and $1.5 \times 10^{-6} \mathrm{~cm}^{2} \mathrm{~V}^{-1} \mathrm{~s}^{-1}$. 1d is found to show higher hole mobility compared to $\mathbf{1 b}$ and $\mathbf{1 c}$.

\section{Conclusion}

Photophysical and hole transport properties of pyrazoline derivatives were studied by experimental and theoretical methods. Pyrazolines can be synthesized in good yields by simple, two-step reactions using relatively cheap starting materials. The UV-visible absorption and fluorescence studies show the intense green emission in both solid state and solution state with non-overlapping absorption and emission 
spectra, which are an important prerequisite for many fluorescence-based applications. Although the electronic properties are not significantly influenced by the substituents, their influence on the charge carrier mobilities can be correlated to their film-forming abilities and reorganization energies. Furthermore, optical, electrochemical, and theoretical measurements show that the HOMO energy levels of pyrazoline lie between -4.8 and $-5.2 \mathrm{eV}$, which are ideal values for hole transport materials. The highest charge carrier mobility measured using the space charge limited current method is found to be in the order of $4 \times 10^{-5} \mathrm{~cm}^{2} \mathrm{~V}^{-1} \mathrm{~s}^{-1}$ for the dimethoxy substituted phenyl moiety. The smaller reorganization energy for the hole than the electron suggests that pyrazolines can be better hole transport materials. This result may provide a new way to further optimize the hole transport materials based on the pyrazoline skeleton. Furthermore, the pyrazolines as HTM in this study are cost-effective, which can also avoid the complicated synthesis of triarylamine derivatives and significantly reduce the cost of devices.

\section{Author contribution}

The manuscript was written through contributions of all authors. All authors have given approval to the final version of the manuscript.

\section{Acknowledgements}

We acknowledge CSIR-TAPSUN (NWP-54) for funding. We thank Prof. P. Ramamurthy and Dr C. Selvaraju, NCUFP, University of Madras for lifetime measurements.

\section{References}

1 V. Coropceanu, J. Cornil, D. A. da Silva Filho, Y. Olivier, R. Silbey and J.-L. Brédas, Chem. Rev., 2007, 107, 926-952.

2 Y. Shirota and H. Kageyama, Chem. Rev., 2007, 107, 9531010.

3 J. Hwang, A. Wan and A. Kahn, Mater. Sci. Eng., R, 2009, 64, 1-31.

4 M. G. Helander, Z. B. Wang, J. Qiu and Z. H. Lu, Appl. Phys. Lett., 2008, 93, 193310.

5 S. Zhong, J. Q. Zhong, H. Y. Mao, J. L. Zhang, J. D. Lin and W. Chen, Phys. Chem. Chem. Phys., 2012, 14, 14127-14141.

6 H.-L. Yip and A. K. Y. Jen, Energy Environ. Sci., 2012, 5, 59946011.

7 P. Škraba, G. Bratina, S. Igarashi, H. Nohira and K. Hirose, Thin Solid Films, 2011, 519, 4216-4219.

8 L. S. C. Pingree, B. A. MacLeod and D. S. Ginger, J. Phys. Chem. C, 2008, 112, 7922-7927.

9 L. S. C. Pingree, B. A. MacLeod and D. S. Ginger, J. Phys. Chem. C, 2008, 112, 7922-7927.

10 S. K. Hau, H.-L. Yip, J. Zou and A. K. Y. Jen, Org. Electron., 2009, 10, 1401-1407.

11 J. Kettle, H. Waters, M. Horie and S. W. Chang, J. Phys. D: Appl. Phys., 2012, 45, 125102.
12 Z. a. Tan, D. Qian, W. Zhang, L. Li, Y. Ding, Q. Xu, F. Wang and Y. Li, J. Mater. Chem. A, 2013, 1, 657-664.

13 J. R. Manders, S.-W. Tsang, M. J. Hartel, T.-H. Lai, S. Chen, C. M. Amb, J. R. Reynolds and F. So, Adv. Funct. Mater., 2013, 23, 2993-3001.

14 G. Li, C.-W. Chu, V. Shrotriya, J. Huang and Y. Yang, Appl. Phys. Lett., 2006, 88, 253503.

15 Y. Kanai, T. Matsushima and H. Murata, Thin Solid Films, 2009, 518, 537-540.

16 T. Yang, M. Wang, Y. Cao, F. Huang, L. Huang, J. Peng, X. Gong, S. Z. D. Cheng and Y. Cao, Adv. Energy Mater., 2012, 2, 523-527.

17 Z. a. Li, T. Ye, S. Tang, C. Wang, D. Ma and Z. Li, J. Mater. Chem. C, 2015, 3, 2016-2023.

18 N. Metri, X. Sallenave, C. Plesse, L. Beouch, P.-H. Aubert, F. Goubard, C. Chevrot and G. Sini, J. Phys. Chem. C, 2012, 116, 3765-3772.

19 C.-Y. Chan, Y.-C. Wong, M.-Y. Chan, S.-H. Cheung, S.-K. So and V. W.-W. Yam, Chem. Mater., 2014, 26, 6585-6594.

20 J.-H. Huang and K.-C. Lee, ACS Appl. Mater. Interfaces, 2014, 6, 7680-7685.

21 C.-Y. Hsu, Y.-C. Chen, R. Y.-Y. Lin, K.-C. Ho and J. T. Lin, Phys. Chem. Chem. Phys., 2012, 14, 14099-14109.

22 Z. Fang, V. Chellappan, R. D. Webster, L. Ke, T. Zhang, B. Liu and Y.-H. Lai, J. Mater. Chem., 2012, 22, 15397-15404.

23 R. A. Klenkler and G. Voloshin, J. Phys. Chem. C, 2011, 115, 16777-16781.

24 H. Choi, S. Paek, N. Lim, Y. H. Lee, M. K. Nazeeruddin and J. Ko, Chem.-Eur. J., 2014, 20, 10894-10899.

25 P. Cias, C. Slugove and G. Gescheidt, J. Phys. Chem. A, 2011, 115, 14519-14525.

26 J. E. Kroeze, N. Hirata, L. Schmidt-Mende, C. Orizu, S. D. Ogier, K. Carr, M. Grätzel and J. R. Durrant, Adv. Funct. Mater., 2006, 16, 1832-1838.

27 T. Leijtens, J. Lim, J. Teuscher, T. Park and H. J. Snaith, Adv. Mater., 2013, 25, 3227-3233.

28 G. Kron, T. Egerter, J. H. Werner and U. Rau, J. Phys. Chem. B, 2003, 107, 3556-3564.

29 D. Poplavskyy and J. Nelson, J. Appl. Phys., 2003, 93, 341-346.

30 P. Stakhira, S. Khomyak, V. Cherpak, D. Volyniuk, J. Simokaitiene, A. Tomkeviciene, N. A. Kukhta, J. V. Grazulevicius, A. V. Kukhta, X. W. Sun, H. V. Demir, Z. Hotra and L. Voznyak, Synth. Met., 2012, 162, 352-355.

31 E. Balasubramaniam, Y. T. Tao, A. Danel and P. Tomasik, Chem. Mater., 2000, 12, 2788-2793.

32 X.-C. Gao, H. Cao, L.-Q. Zhang, B.-W. Zhang, Y. Cao and C.-H. Huang, J. Mater. Chem., 1999, 9, 1077-1080.

33 Z. Lu, Q. Jiang, W. Zhu, M. Xie, Y. Hou, X. Chen and Z. Wang, Synth. Met., 2000, 111-112, 465-468.

34 S. Takeshi, F. Takanori, N. Yoshitaka, H. Yuji, S. Kenichi and K. Kazuhiko, Jpn. J. Appl. Phys., 1995, 34, 3124.

35 X. H. Zhang, S. K. Wu, Z. Q. Gao, C. S. Lee, S. T. Lee and H. L. Kwong, Thin Solid Films, 2000, 371, 40-46.

36 P. M. Borsenberger and L. B. Schein, J. Phys. Chem., 1994, 98, 233-239. 
37 R. B. Aher, G. Wanare, N. Kawathekar, R. R. Kumar, N. K. Kaushik, D. Sahal and V. S. Chauhan, Bioorg. Med. Chem. Lett., 2011, 21, 3034-3036.

38 S. Easwaramoorthi, B. Umamahesh, P. Cheranmadevi, R. S. Rathore and K. I. Sathiyanarayanan, RSC Adv., 2013, 3, 1243-1254.

39 W. H. Melhuish, J. Phys. Chem., 1961, 65, 229-235.

40 D. Vak, B. Lim, S.-H. Lee and D.-Y. Kim, Org. Lett., 2005, 7, 4229-4232.

41 A. M. Nardes, M. Kemerink, M. M. de Kok, E. Vinken, K. Maturova and R. A. J. Janssen, Org. Electron., 2008, 9, 727-734.

42 H. Dong, H. Zhu, Q. Meng, X. Gong and W. Hu, Chem. Soc. Rev., 2012, 41, 1754-1808.

43 J. Hirsch, J. Phys. C: Solid State Phys., 1979, 12, 321.

44 B. C. Lin, C. P. Cheng, Z.-Q. You and C.-P. Hsu, J. Am. Chem. Soc., 2005, 127, 66-67.

45 X. Yang, L. Wang, C. Wang, W. Long and Z. Shuai, Chem. Mater., 2008, 20, 3205-3211.

46 N. S. Hush, J. Chem. Phys., 1958, 28, 962-972.

47 R. A. Marcus, Rev. Mod. Phys., 1993, 65, 599-610.

48 J. Yin, S.-L. Zhang, R.-F. Chen, Q.-D. Ling and W. Huang, Phys. Chem. Chem. Phys., 2010, 12, 15448-15458.

49 A. G. Baboul, L. A. Curtiss, P. C. Redfern and K. Raghavachari, J. Chem. Phys., 1999, 110, 7650-7657.

50 G. W. T. M. J. Frisch, H. B. Schlegel, G. E. Scuseria, M. A. Robb, J. R. Cheeseman, G. Scalmani, V. Barone, B. Mennucci, G. A. Petersson, H. Nakatsuji, M. Caricato, X. Li, H. P. Hratchian, A. F. Izmaylov, J. Bloino, G. Zheng,
J. L. Sonnenberg, M. Hada, M. Ehara, K. Toyota, R. Fukuda, J. Hasegawa, M. Ishida, T. Nakajima, Y. Honda, O. Kitao, H. Nakai, T. Vreven, J. A. Montgomery Jr, J. E. Peralta, F. Ogliaro, M. Bearpark, J. J. Heyd, E. Brothers, K. N. Kudin, V. N. Staroverov, R. Kobayashi, J. Normand, K. Raghavachari, A. Rendell, J. C. Burant, S. S. Iyengar, J. Tomasi, M. Cossi, N. Rega, J. M. Millam, M. Klene, J. E. Knox, J. B. Cross, V. Bakken, C. Adamo, J. Jaramillo, R. Gomperts, R. E. Stratmann, O. Yazyev, A. J. Austin, R. Cammi, C. Pomelli, J. W. Ochterski, R. L. Martin, K. Morokuma, V. G. Zakrzewski, G. A. Voth, P. Salvador, J. J. Dannenberg, S. Dapprich, A. D. Daniels, Ö. Farkas, J. B. Foresman, J. V. Ortiz, J. Cioslowski, and D. J. Fox, Gaussian, Inc., Wallingford CT, 2009.

51 E. Varathan, D. Vijay and V. Subramanian, J. Phys. Chem. C, 2014, 118, 21741-21754.

52 E. Varathan, D. Vijay, P. S. Vinod Kumar and V. Subramanian, J. Mater. Chem. C, 2013, 1, 4261-4274.

53 M.-K. Yan, Y. Tao, R.-F. Chen, C. Zheng, Z.-F. An and W. Huang, RSC Adv., 2012, 2, 7860-7867.

54 T. Koopmans, Physica, 1934, 1, 104-113.

55 G. P. Owen and A. Charlesby, J. Phys. C: Solid State Phys., 1974, 7, L400.

56 V. K. C. Kao and W. Hwang, Electrical transport in solids with particular reference to organic semiconductors, Pergamon Press Oxford, 1981.

57 M. Planells, A. Abate, D. J. Hollman, S. D. Stranks, V. Bharti, J. Gaur, D. Mohanty, S. Chand, H. J. Snaith and N. Robertson, J. Mater. Chem. A, 2013, 1, 6949-6960. 